\title{
Potency Determination of Essential Drug Samples Manufactured By Small and Medium Pharmaceutical Industries in Bangladesh
}

\author{
Ononna $\mathrm{HF}^{1}$, Al Hossain ASMM ${ }^{1}$, Ganguly $\mathrm{A}^{2}$, Faroque ABM ${ }^{1}$ \\ ${ }^{I}$ Department of Pharmaceutical Technology, University of Dhaka, Dhaka, Bangladesh \\ ${ }^{2}$ Department of Clinical Pharmacy and Pharmacology, University of Dhaka, Dhaka, Bangladesh \\ e-mail:abmfaroque@yahoo.com
}

\begin{abstract}
Drugs are considered highly essential and sensitive items for saving lives. Pharmaceutical sector in Bangladesh has grown from strength to strength over the last 40 years and evolved from an import dependent to self-reliant, export oriented sector. But counterfeit, adulterated and sub-standard drugs, though small in percentage, still remain to be a threat in the local market. This cross sectional study was conducted during March to September 2016, with the purpose of this study is to determine potency of some essential drugs, which were used vigorously by sub-urban and rural people and manufactured by randomly selected small and medium pharmaceutical industries of Bangladesh. The study revealed that the measured potency of different essential drugs manufactured by randomly selected small pharmaceutical industries was mostly unsatisfactory. Here, it has been found that most of the drug samples did not match with the acceptance level: the potency of Amoxicillin tryhydrate capsule was found $8.25 \%, 47.9 \%, 51.1 \% 19.06 \%, 57.06 \%$ from five different pharmaceutical industries and for Diclofenac Sodium is $44.9 \%, 26.8 \%, 27.2 \%, 29.9 \%, 19.4 \%, 62.12 \%, 15.9 \%$ and $60.76 \%$ from eight different industries. So, the Drug Administration should have a strict monitoring and controlling mechanism to the distribution of those drugs, otherwise the overall public health of the country will be at stake.
\end{abstract}

Keywords: Drug potency, Small pharmaceutical industries, Sub-standard drugs

\section{Introduction}

Drugs are used to protect, cure and mitigate disease states, but these drugs may cause damage to health, and even death. While Bangladeshi pharmaceutical industries have reached the height of supplying $98 \%$ of the country's annual drug market and increased the country's credibility in the international markets; counterfeit, adulterated and sub-standard drugs, though small in percentage, still remain to be a threat in the local market. ${ }^{1-2}$ As reported in the media, in the absence of strict monitoring and effective control by the regulatory authority, some medium and small pharmaceutical companies are being involved repeatedly in manufacturing and marketing of counterfeit, adulterated and sub-standard drugs.

Though many factories have been already closed and license of many companies have been suspended, counterfeit, adulterated and sub-standard drugs are still reported to be extensively available mainly in the small townships and the rural areas. In the absence of proper control of the countryside, these drugs are on the market to take advantage of unconsciousness of the common people. Users of these drugs do not get the desired therapeutic effects in spite of spending their hard-earned money. Some specified drug business holders with their organized syndicates are responsible for this proliferation of counterfeit, adulterated and sub-standard drugs in the rural countryside areas.

Studies showed that some companies that are engaged in producing sub-standard drugs intentionally mimic products of some big pharmaceutical companies in fixing trade names and designing of packages and labels with a view to selling these products in the market at a cheaper rate. Sometimes these companies just supply these drugs only to the Mitford Market of Dhaka and then, from there those mimicked drugs are distributed throughout the whole country. These companies do not have their own marketing department. ${ }^{3-4}$

So, the main objective of this study is to evaluate the potency of the finished drugs that 
are being produced and marketed by the small and medium scale pharmaceutical industries in Bangladesh.

\section{Materials and Methods}

This cross sectional study was conducted during March to September 2016 for potency determination of some randomly collected essential drug samples, Active Pharmaceutical Ingredients (API) of eight different drugs were collected. Analytical pure standard samples of eight different drugs were received as a kind gift samples from renowned pharmaceutical industries of Bangladesh. These were used without further purification. Name of the APIs are-Amoxicillin Trihydrate, Azithromycin, Cephradine, Cefixime Trihydrate, Ciprofloxacin Hydrochloride, Diclofenac Sodium, Metronidazole, Ranitidine Hydrochloride. For potency determination of drugs, different chemicals and solvents were used. They wereHydrochloride acid, Methanol, Sodium Hydroxide, Monobasic Potassium phosphate, Acetoniotrile and Distilled water. Except Azithromycin, potency of other generic drug samples were analysed by UV-visible Spectrophotometry method developed by Nayon $M$ et al, Naveed $S$ et al, Omar SARR $S$ et al and others and for Azithromycin, HPLC method was adopted (USP 30-NF 25).

The drug samples were randomly collected from the rural areas of different Upazila of Dhaka, Jamalpur, Faridpur, Magura, Pirojpur, Barisal, Chandpur, Rangpur, Habiganj and Chittagong, which were manufactured by small and mediam pharmaceutical industries of Bangladesh. Laboratory analyses were done in Pharmaceutical Lab of the Department of Pharmaceutical Technology of the University of Dhaka and Quality Control Lab of Research and Development, Incepta Pharmaceutical Ltd. These pharmaceutical industries were enlisted in the categories of D, E and F in the $1^{\text {st }}$ report of the Specialist Inspection Team that was constituted by the Parliamentary Standing Committee of Ministry of Health and Family Welfare in 2010.
In this study, for potency determination, different sample brands of each generic drug were collected. However, the number of collected brand sample varied due to availability of sample brand. Table-1 indicates the number of brand sample that were collected for analysis. Each sample was tested three times to ensure correct potency.

\section{Potency determination of drug samples}

For the potency determination of Cefixime trihydrate, sevensamples of Cefixime trihydrate tablets of different companies were randomly collected from different areas of Bangladesh. The standard stock solution of $100 \mu \mathrm{g} / \mathrm{mL}$ of cefixime trihydrate was prepared andwas used as standard stock solution

Table I :Number of trade name sample for each generic drug that was analysed

\begin{tabular}{|c|c|c|c|c|c|c|c|c|}
\hline & \multicolumn{8}{|c|}{ Name of Generic Drug Molecules } \\
\hline & 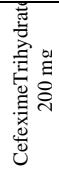 & 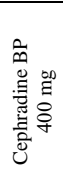 & 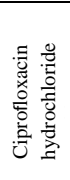 & 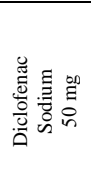 & 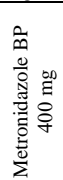 & 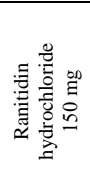 & 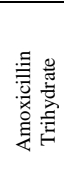 & 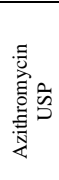 \\
\hline $\begin{array}{l}\text { No } \\
\text { Collected } \\
\text { Drug } \\
\text { Samples }\end{array}$ & 7 & 6 & 6 & 8 & 7 & 3 & 6 & 7 \\
\hline
\end{tabular}

Further dilutions were made with distilled water to obtain differentconcentrations andt he absorbance of the spectra was measured at 287 $\mathrm{nm}$. The calibration curves were then constructed by plotting absorbance versus concentration and the regression equations were calculatedUV- visible spectrophotometry . method developed by Nayon $\mathrm{M}$ et al, was used to determine the potency of these randomly collected samples. ${ }^{5}$

Twenty capsules of samples were dissembled and weight of content of each capsule was taken. The contents were grinded to make fine powder. Appropriate dilution of sample solution was prepared and absorbance was recorded. The concentration of the drug was determined from the regression equation of standard drug. After then, the potency of nine marketed products of cefixime trihydrate was calculated in percentage. 
In addition, for rest of the generic drug samples except Azithromycin, the methodology followed

forCefixime trihydrate was also followed for those generic drug samples. Specifically, Naveed et al., for Cephradine, Omar S et al, for Ciprofloxacin, Pandey et al, for Diclofenac Sodium, Das et al, for Metronidazole, Salve et $a l$, for Ranitidine and Rele et $a l$, for Amoxicillin were adopted respectively for potency determination of these generic drug samples. ${ }^{6-11}$ Azithromycin USP pure drug was obtained as a gift sample from one of the top Pharmaceutical industries of Bangladesh. For the potency determination of Azithromycin, seven samples of Azithromycin tablets of different companies were randomly collected from different areas of Bangladesh.

\section{Preparation of mobile phase}

Buffer: $4.6 \mathrm{~g}$ of monobasic potassium phosphate anhydrous was transferred to a $1000 \mathrm{~mL}$ volumetric flask and diluted with water to volume. Then it was adjusted with $1 \mathrm{~N}$ sodium hydroxide to a $\mathrm{pH}$ of 7.5 and diluted with water to 1L.Then mobile phase was prepared by filtering and degassing the mixture of acetonitrile and buffer. ((65:35 Preparation of standard Azithromycin solution: First of all, standard azithromycin solution was prepared by taking $10 \mathrm{mg}$ of USP Azithromycin RS in a 10$\mathrm{mL}$ volumetric flask. Then solution of mobile phase was added up to the mark and sonicated to obtain a solution having a concentration of $1 \mathrm{mg} / \mathrm{mL}$ of Azithromycin.

Preparation of sample solution:Seven market products of Azithromycin were collected. Twenty tablets from each formulation were weighed and finely powdered. An accurately weighed portion of the powder, equivalent to about $50 \mathrm{mg}$ of Azithromycin was transferred to a $-50 \mathrm{~mL}$ volumetric flask. The solution of mobile phase $25 \mathrm{~mL}$ was added up to the mark and sonicated for not less than 15 minutes. The solution was allowed to equilibrate to room temperature, diluted with mobile phase to volume and mixed to obtain a solution having a nominal concentration of $1 \mathrm{mg}$ of Azithromycin per $\mathrm{mL}$. Sample solutions of seven market products were prepared following this method.

Analysis:Samples: Standard solution sand sample solution
The percentage of the labeled amount of Azithromycin $\left(\mathrm{C}_{38} \mathrm{H}_{72} \mathrm{~N}_{2} \mathrm{O}\right.$ (12 in the portion of tablets taken: Result $=\left(\mathrm{r}_{\mathrm{u}} \mathrm{r}_{\mathrm{s}}\right) \times(\mathrm{Cs} / \mathrm{Cu})$ $\times \mathrm{P} \times \mathrm{F} \times 100$

$r_{u}=$ peak response of Azithromycin from the sample solution, $\mathrm{r}_{\mathrm{s}}=$ peak response of Azithromycin from the standard solution, Cs = concentration of USP Azithromycin RS in the standard solution $(\mathrm{mg} / \mathrm{ml}), \mathrm{Cu}=$ nominal concentration of Azithromycin in the sample solution $(\mathrm{mg} / \mathrm{ml}), \mathrm{P}=$ Potency of USP Azithromycin RS $(\mu \mathrm{g} / \mathrm{mg}) \quad, \mathrm{F}=$ conversion factor, $0.001 \mathrm{mg} / \mathrm{ml}$;Acceptance criteria: $-\% 90$ $\% 110$

The potency of collected drug samples was determined using standard curve of respective drugs (Except Azithromycin drug samples). The potency of Azithromycin drug samples was measured using HPLC method according to USP monograph ${ }^{12}$.

The standard curves of drugs were constructed by plotting different concentration of standard solution ofdrugin $\mathrm{X}$ axis and measured absorbance at definite wavelength of respective concentration in $\mathrm{Y}$ axis. The regression equation .was also determined from the standard curve The standard curve with regression equation has been given in figure-1.7-1.1

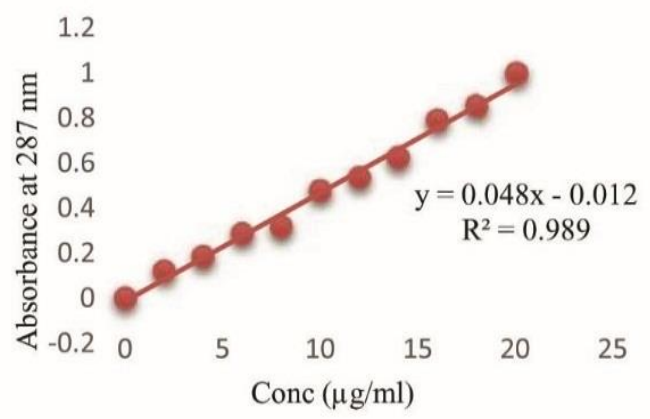

Fig 1.1 Standard Curve for Cefexime Trihydrate

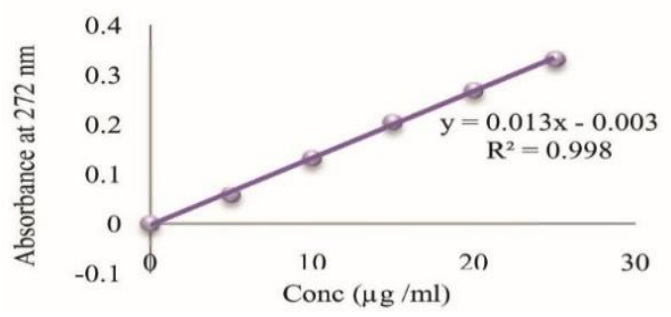

Fig 1.2 Standard Curve of Cephradine 


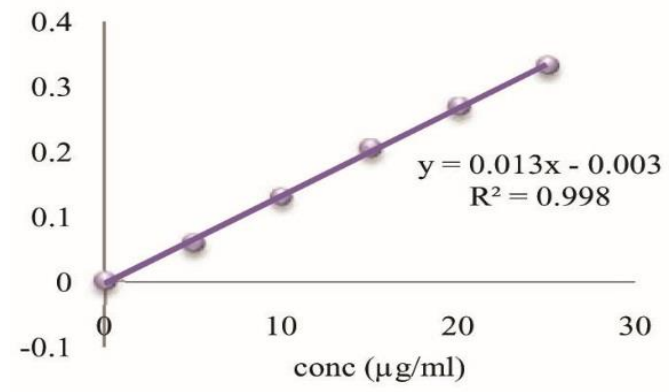

Fig 1.3 Standard Curve for Ciprofloxacin HCI

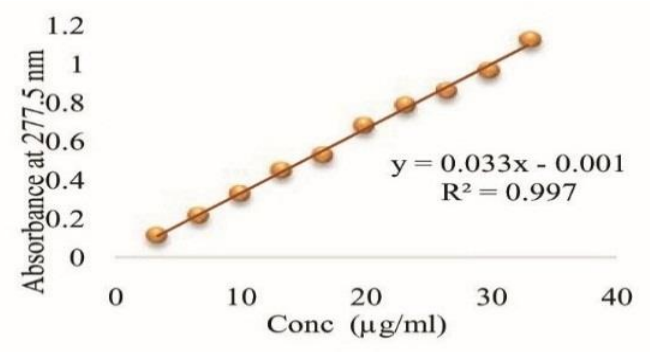

Fig 1.4 Standard Curve for Diclofenac Sodium

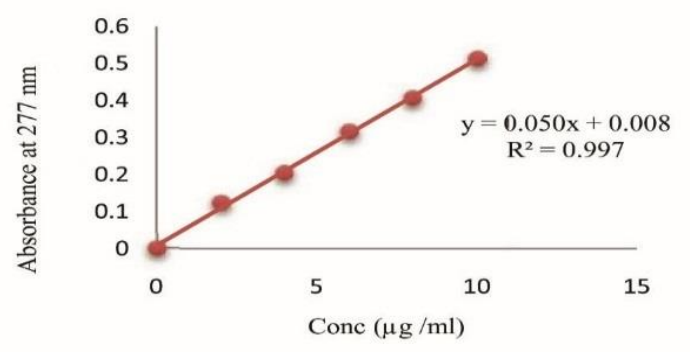

Fig 1.5 Standard Curve of Metronidazole

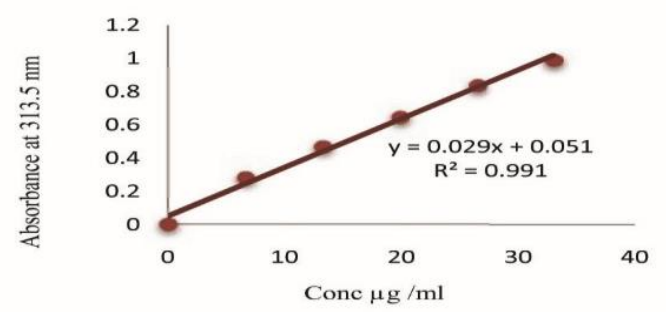

Fig 1.6 Standard Curve of Ranitidine Hydrochloride

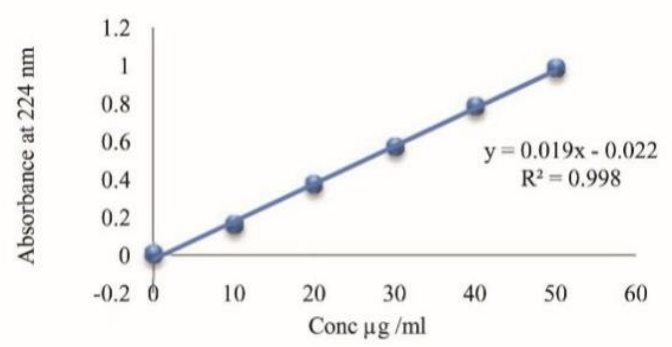

Fig 1.7 Standard Curve for Amoxicillin Trihydrate
After preparing sample solution of drug samples, the absorbance value (y) of respective samples were measured at same wavelength as standard curve. Then absorbance found with unkonwn concentration were placed in the equation and the concentration (x) of the drug samplesweremeasured. The determined concentration were multiplied with the proper dilution factor and the actual amount of drug in the samplewere calculated.

\section{Results}

Amount (mg) of drug actually found in commercial samples after analysis is shown in table I and the potency of different drug samples manufactured by different small and medium pharmaceutical companies in Bangladesh shown in (Table- II).

Table II: Amount (mg) of drug actually found in commercial samples after analysis

\begin{tabular}{lccccccccc}
\hline & & & & & \\
& & & \\
\end{tabular}

From the above results, it has been found that most of randomly collected drugs samples of different pharmaceutical industries did not 
match with the acceptance level. These industries were enlisted in the categories D, E and $\mathrm{F}$ in the $1^{\text {st }}$ Report of the Specialist Inspection Team that was constituted by the Parliamentary Standing Committee in 2010

For the determination of potency of the drug samples, mainly simple UV Spectrophotometric methods were applied. According to USP monograph, each of tablet or capsule should contain not less than 90 percent and not more than 110 percent of drugs to their label claim. In this study, drug samples from eighteen pharmaceutical industries were randomly collected. Amongst these industries, a few have comparatively better potency than others. Some have moderate drug potency but still they are far from fulfilling the acceptance level. All other samples have very unsatisfactory results. (figure 2-9)

Table III: Potency of different commercial samples analyzed

\begin{tabular}{|c|c|c|c|c|c|c|c|c|}
\hline \multirow[t]{2}{*}{ Drug samples } & \multicolumn{8}{|c|}{ Potency (\%) } \\
\hline & $\begin{array}{c}\text { Cefexime } \\
\text { Trihydrate } \\
200 \text { mg Capsule }\end{array}$ & $\begin{array}{c}\text { Cephradin } \\
\text { BP } \\
400 \mathrm{mg} \text { Capsule }\end{array}$ & $\begin{array}{c}\text { Cipro- } \\
\text { floxacin } \\
\text { HCl } \\
500 \mathrm{mg} \\
\text { Tablet }\end{array}$ & $\begin{array}{c}\text { Diclofenac } \\
\text { Sodium } 50 \mathrm{mg} \\
\text { Tablet }\end{array}$ & $\begin{array}{c}\text { Metronidazole } \\
\text { BP } \\
400 \text { mg Tablet }\end{array}$ & $\begin{array}{c}\text { Ranitidin } \\
\text { HCl } \\
150 \mathrm{mg} \\
\text { Tablet }\end{array}$ & $\begin{array}{l}\text { Amoxicillin } \\
\text { Trihydrate } \\
\mathbf{5 0 0} \mathbf{~ m g} \\
\text { Capsule }\end{array}$ & $\begin{array}{c}\text { Azithromy } \\
\text { cin USP } \\
500 \text { mg Tablet }\end{array}$ \\
\hline CompanyA & & & & & & 64.2 & & \\
\hline CompanyB & 64.5 & & & 44.9 & & & & \\
\hline Company $\mathrm{C}$ & & & & 26.8 & & & & \\
\hline Company D & & 58.9 & 70.4 & 27.2 & & & 57.5 & \\
\hline Company $\mathbf{E}$ & 51.2 & 48.9 & 53.4 & 29.9 & 56.2 & 57.8 & & \\
\hline Company F & & & & & & & 51.1 & \\
\hline Company $\mathbf{G}$ & & & & & 44.9 & & & \\
\hline Company $\mathbf{H}$ & & & & 19.4 & 14.8 & & & \\
\hline Company I & & & & & & & 19.06 & \\
\hline Company $\mathbf{J}$ & 69.14 & 75.9 & 66.4 & 62.12 & 68.6 & & 75.3 & 104.14 \\
\hline Company K & & 56.6 & 51.04 & & 45.9 & & & 87.8 \\
\hline Company L & & & & & & & & 68.6 \\
\hline Company M & & & & 15.9 & & 49.7 & & \\
\hline Company N & 71.2 & & & & & & & \\
\hline Company $\mathbf{O}$ & 2.22 & 1.04 & 1.53 & & 4.9 & & 8.25 & 2.49 \\
\hline Company $\mathbf{P}$ & & & & & & & & 94.8 \\
\hline Company $\mathbf{Q}$ & 53.5 & & & & & & & 92.7 \\
\hline Company $\mathbf{R}$ & & & & & & & 47.9 & 68.5 \\
\hline Company $\mathbf{S}$ & 74.26 & 60.54 & 82.02 & 60.76 & 63.8 & & & \\
\hline
\end{tabular}

In addition, those collected drugs have low physical as well as packaging qualities. The finishing and coating of tablets of those drug samples were mostly questionable. The hardness of the tablets was also very low. Again, some have other physical problems like capping, lamination and sticking. Packaging design of some big companies were also copied by some of these companies.

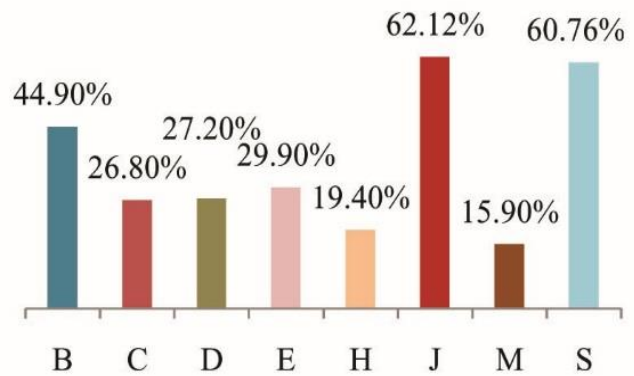

Fig-2: Potency of seven randomly collected marketed products of Cefixime Trihydrate Capsule

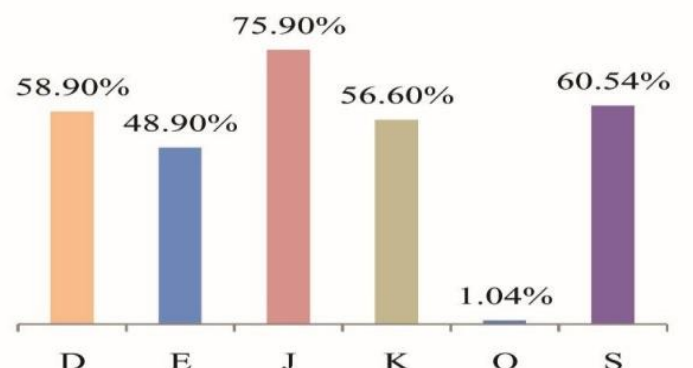

Fig-3: Potency of six randomly collected marketed products of Cephradine Capsule

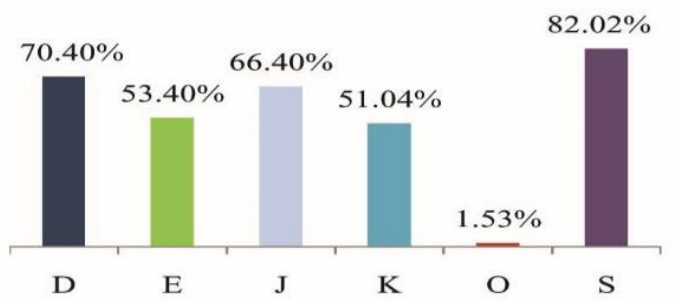

Fig-4: Potency of six randomly collected marketed product s of CiprofloxacinHCl Tablet 


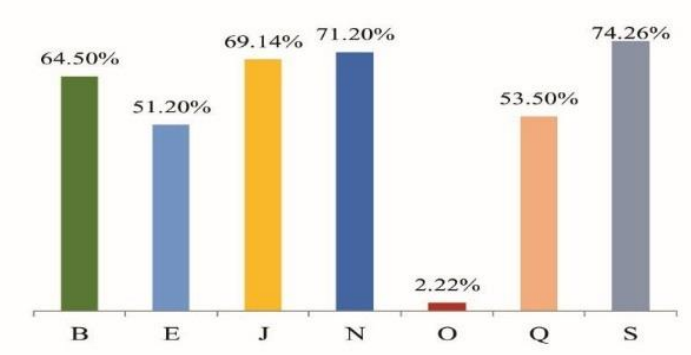

Fig-5: Potency of eight randomly collected marketed products of Diclofenac Sodium Tablet

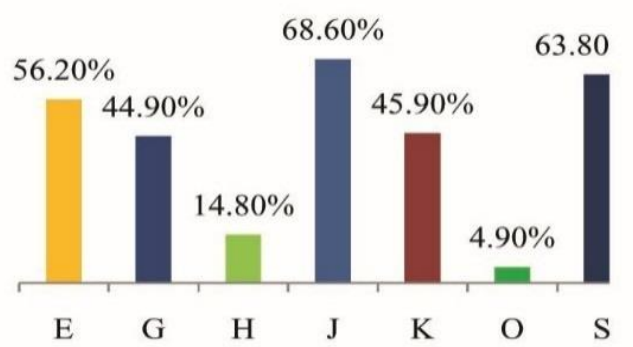

Fig-6: Potency of seven randomly collectd samples of Metronidazole Tablet

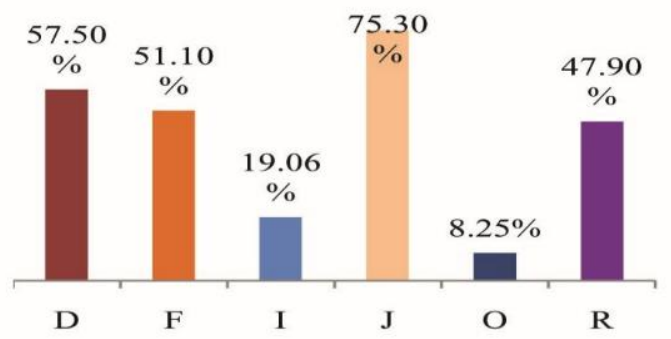

Fig-7: Potency of three randomly collected marketed products of Ranitidine Hydrochloride Tablet

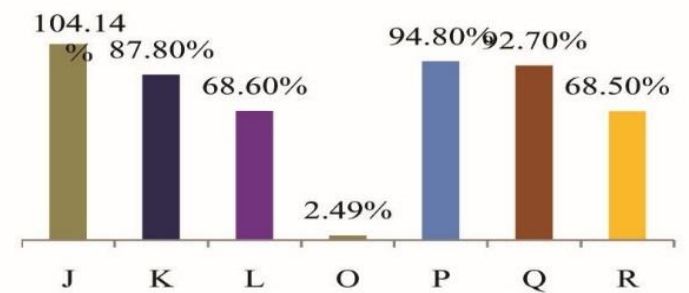

Fig-8: Potency of six randomly collected marketed products of Amoxicillin Trihydrate Capsule

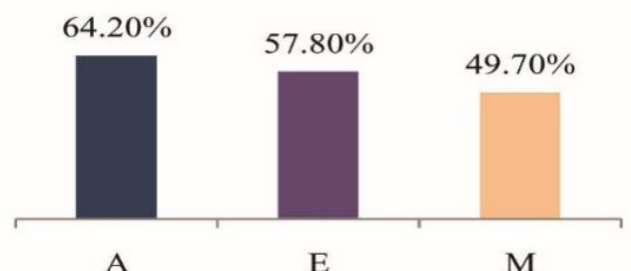

Fig-9: Potency of seven randomly collected marketed products of Azithromycin Tablet

\section{Discussion}

Drugs of these industries are extensively available in the rural and countryside areas of Bangladesh. They were not found in Dhaka city or other city areas. The study opens a hard reality that though drugs are a commodity where quality and potency cannot be compromised, some middle and small pharmaceutical industries are engaged in producing substandard drugs. This is an important public health threat. It is especially true in case of antibiotics. Azithromycin, Amoxicillin, Ciprofloxacin, Cephradine, Cefixime etc. are widely used antibiotics in the country because these are very effective weapons against microbial diseases prevailing in the country. But as these antibiotics are not being manufactured by maintaining proper protocol, they cannot cure these deadly diseases. Moreover, these substandard antibiotics are causing development of drug-resistant microorganisms that are again an additional threat both for the present and coming generations. ${ }^{13}$

To prevent this public health menace, immediate measures should be taken by the government to save our population. The industries that have been engaged in manufacturing these substandard drugs should be awarded strong exemplary punishment like cancellation of their manufacturing license, rigorous imprisonment, huge fine and confiscation of their properties.

Moreover, the study also focus that these industries are marketing their sub-standard drugs in the remote rural areas where monitoring by the Drug Administration is feeble or absent. Taking this opportunity, these companies in collaboration with the retail drug stores are selling their sub-standard products. Thus, it is urged that as a regulatory body, the Drug Administration should improve their monitoring activities effectively so that no substandard drug can infiltrate the market and cause damage to public health. One of the reasons as to why some middle and small pharmaceutical industries have been engaging themselves to produce sub-standard drugs can be that they do not have the necessary manufacturing facilities to produce standard quality drugs. In this case, before issuing a new or renewing an existing manufacturing license authority must ensure that 
all required facilities are being present in the premise of the industry.

\section{Conclusion}

In this study, potency of some randomly selected essential drug samples of some medium and small pharmaceutical industries of Bangladesh were analyzed and found unsatisfactory. As drugs are for the well being of health and health can't be risked, thus proper regulatory control and monitoring should be applied for the distribution of these sub-standard drugs manufactured by the medium and small pharmaceutical industries of Bangladesh. Based on the findings of the study, it is recommended that the Drug Administration should come out of its monitoring limitations, and introduce a strengthened and transparent monitoring mechanism covering the whole chain across the country; manufacturing licenses should not be renewed or issued to drug companies which are non compliant with the WHO's GMP Guidelines of 1975 and standards set out under the laws and regulations of the country; and licenses of such companies may be cancelled or suspended until the satisfactory correction. Furthermore, for small and medium pharmaceutical companies, the Drug Administration should stop issuing product registration of high technology drugs or drugs that need dedicated areas and machines to manufacture such as antibiotics. These types of product registrations already issued to these companies may be withdrawn or suspended immediately.

\section{References}

1. Tazin F. Pharmaceutical Industry of Bangladesh: Progress and Prospects. The Millennium University Journal. 2016;1:19-20.

2. Kabir K. Bangladesh Pharma Industry: Opportunities in Global Generics [Internet]. 2016 p. 4-5. Available at www.jetro.go.jp /ext_images/world/asia/bd/seminar_reports/2016 0413/p4.pdf

3. Rabbi, R. (2015). The Harmful Effects of Adulterated Medicine. The Daily Jugantor, [online] p.1. Available at:www.jugantor.com /old/first-page/2015/08/04/302467 [Accessed 15 Jul 2016].

4. Mahmud S. Did not Stop Adulterated and Substandard Drugs. Bangladesh Protidin [Internet]. 2015 [cited 5 June 2016];:12. Available at: http://www.ebdpratidin.com/arc /pre_page /2015-11-24/12

5. Nayon AU, Nesa J, Uddin MN, Amran MS, Bushra U.Development and validation of UV Spectrometric Method for the Determination of Cefixime trihydrate in Bulk and Pharmaceutical Formulation. 2013;301-05.

6. Naveed S, Jaweed L. UV Spectrophotometric Assay of Different Brands of Cephradine. Health Sciences Research. 2014; 1:84-7.

7. Sarr SO, Fall D, Ndiaye SM, Diedhiou A, Diop A, Ndiaye B, Diop YM. Development and validation of a simple and economical spectrofluorimetric method for estimation of quinine in pharmaceutical dosage forms. Int $\mathrm{J}$ of Biol and Chem Sci. 2013; 7:366-76.

8. Pandey G. Spectrophotometric methods for estimation of diclofenac sodium in tablets. Int $\mathbf{J}$ of Biomedand Adv Res. 2013; 4:77-82.

9. Das J, Dhua M. UV-spectrophotometric assay method development and validation of metronidazole in bulk and tablet formulation. $\mathrm{J}$ of Pharm Sci Tech. 2014; 3:109.

10. Salve P, Gharge D, Kirtawade R, Dhabale P, Burade K. Simple validated spectroscopic method for estimation of Ranitidine from tablet formulation. Int J Pharm Tech Res. 2010; 2:2071-4.

11. Rele R.Simultaneous UV-Spectrophotometric estimation of amoxicillin and carbocisteine by area under curve method in combined dosage form. 2015;5:1-7.

12. United States Pharmacopeia and National Formulary (USP 30-NF 25).Rockville, MD: United States Pharmacopeial Convention; 2007.

13. Knobler S. The resistance phenomenon in microbes and infectious disease vectors. Washington, D.C.: National Academies Press; 2003. 